\title{
A STUDY ON RENEWABLE ENERGY SOURCES AND MICROBIAL FUEL CELLS
}

\author{
S Venkata Raju \\ Assistant Professor \\ Department of Physics \\ D.N.R Degree college, \\ BHIMAVARAM, West Godavari Dt. A.P \\ K Madhusudhana \\ Department of Physics \\ Mahaveer Institute of Science and Technology \\ Bandlaguda, \\ HYDERABAD, Telangana.
}

\begin{abstract}
Renewable energy is the energy created by sources, which are naturally replenished such as sunlight, rain, wind and tides. Although there is much debate about how to define and distinguish renewable energy from non-renewable, other energy types such as biomass, biofuel and anaerobic digestion are also widely considered as renewable energy. Microbial fuel cells(MFCs) that generate electricity by the break-down of organic matter(e.g. wastewater) have a great potential for the future energy and environmental challenges. MFCs are often compared with anaerobic digestion, which also uses microbial activity for breaking down organic matter in the absence of oxygen. Unlike anaerobic digestion, which is relatively well understood and already widely used in municipal wastewater treatment plants, MFCs have received far less attention and funding, hence the technology is still at laboratory level in its development.
\end{abstract}

Key Words: cells, energy, fuel, microbial, renewable, solar, sources.

Some of the major renewable energy sources are as follows:

\section{Solar Energy:}

Theoretically energy from the sun is the most abundant renewable electricity source on the earth and could supply more than enough of the energy the world needs (Lewis \& Nocera, 2006; Amanet al., 2015). Although the sun's movements are easily predictable, the possible amount of solar energy gaining highly depends on global location and climatic condition. One of the advantages of this technology is on-site electricity generation. It is flexible in terms of powering scale. For example, photovoltaic cells can be used for powering

small electrical devices such as watches and calculators as well as large grid-connected solar farms. It is also a relatively wellunderstood technology and low running costs make the technology more attractive. However the solar cell material is highpriced and its environmental impact should not be overlooked 


\section{IJO-SCIENCE \\ (INTERNATIONAL JOURNAL ONLINE OF SCIENCE) \\ Volume II, Issue VII October 2016}

ISSN: $2455-0108$

\section{Wind Power}

Wind energy can be converted into electricity (via wind turbines) and mechanical power(via wind mills). Again this is highly dependent on location. The UK has a big merit due to climatic condition. Consequently wind power (onshore and off shore) has been growing fast for the last decade in the UK. Wind power is a readily available resource and does not emit air pollution. Onshore wind farms are relatively cheap to build and remove. Although off shore wind farms produce far more energy than onshore types, it is one of the most expensive ways of generating electricity per unit due to the logistics of construction, connection and maintenance. Another disadvantage to consider is its impact on wild life and local ecosystem (Baidya Roy, Pacala \& Walko, 2004).

\section{Hydropower}

Hydropower is electricity converted from the kinetic energy of flowing water through a turbine. It is one of the oldest forms of electricity generation in the world. Hydropower is the largest renewable energy source and accounts for around $16.5 \%$ of the world's electricity generation International Renewable Energy Agency, 2012). Compared to other electricity generation facilities of a similar scale, hydropower plants are relatively cheap and easy to maintain. Also, they can be turned on and off as required. The down side of hydropower is its social and environmental cost. Building a power plant usually causes flooding of the nearby area and can bring damage to local ecosystems.

\section{Tidal Power}

Tidal power is a kind of hydropower that is converted from the kinetic energy of tides into electricity. It is not widely used as yet, but has attracted much attention recently. Tides can be more easily predicted than solar or wind energy, which enables more stable energy supply as firm power (Sleiti,
2015). However high cost for construction needs to be improved to make the technology cost-compatible on the global energy market.

\section{Biomass}

Biomass refers to organic material originated from living organisms. Broadly speaking, this can include organic matter of all kinds; plants, animals or waste from organic sources. It is one of the most plentiful and well-utilised sources of renewable energy on the planet. Biomass is considered to be a renewable energy source, because the organic carbon contained within it, is oxidized and released back into the atmosphere, but is only equivalent to that which was captured by photosynthesis in the first place, and that which the biomass is bound to release as part of its natural cycle of food chains and respiration. It is therefore part of the planet's immediate carbon cycle, rather than being part of the geologic fossil fuel cycles. However, a cautious and considerate approach is needed for achieving truly sustainable biomass, although the types of biomass and range of technology for its use are very wide.

One of the biggest concerns surrounding biomass controversy is deforestation resulted from biomass production (plants in particular).This has been an on-going issue especially in the Developing World. Soil erosion, loss of biodiversity, increasing consumption of water and fertilizer can also be brought about by biomass production. Diverting the land use from food crops to biofuels may lead to an increase in food prices and hunger (International Energy Agency, 2010). The life-cycle greenhouse-gase missions of biomass are again unclear. In 2010, the Manomet study reported that in the case of generating electricity in utilityscale plants, net carbon emissions are higher from biomass than fossil fuels, even 


\section{IJO-SCIENCE \\ (INTERNATIONAL JOURNAL ONLINE OF SCIENCE) \\ Volume II, Issue VII October 2016}

ISSN: $2455-0108$

taking forest regrowth into consideration (Manomet Center for Conservation Sciences, 2010). The study claimed that the net carbon emissions after 40 years, are higher from biomass than coal for generating electricity since moreCO2 is released than would be released if the equivalent coal, oil or natural gas was burnt. A recent study (Röder, Whittaker \& Thornley, 2015) also pointed that green house-gas emissions from bioenergy of forest residues can be worse than coal when considering the whole supply chain stages.

\section{Energy from Waste}

Despite of the multilateral efforts for improving the World's energy problems, it is quite clear that there is no 'panacea' or' one perfect solution'. As discussed earlier, all the available renewable energy sources have their own limitations. Nevertheless these efforts should not be stopped and more technological innovations through research and innovation need to be achieved.

Although the term is often subjective, it is generally accepted that waste implies unwanted or unusable material that needs to be disposed of. However with the advancement of technology, waste can sometimes become a source of energy. Energy from waste is a very attractive option. The useable form of energy from waste can include electricity and heat. This approach is about reducing or recovering some of the energy that is spent in running the system; for example the energy cost of waste treatment and mass transfer. The most common way of implementation is incineration of waste. For the last few decades, the efficiency and unwanted emission of gases have been considerably improved for these treatments. But this approach is only suitable if the waste material is sufficiently dry; energy cannot be gained without additional energy input unless the water content of waste is below about 30 $\%$ (McCarty ,Bae \& Kim, 2011).Thus different approaches are required for recovering energy from 'wet waste' such as waste water.

Over 10 billion litres of wastewater are produced on a daily basis, at domestic and industrial levels, in England and Wales. It takes approximately $6.34 \mathrm{GWh}$ of energy per day to treat this volume of sewage, which accounts for almost $1 \%$ of the daily electricity consumption in the country (Parliamentary Office of Science and Technology, 2007). Wastewater contains energy, in the form of biodegradable organic matter. According to Heidrich et al.(2011), the internal chemical energy contained in UK domestic waste water is

$7.6 \mathrm{~kJ} / \mathrm{L}$.

In this respect, microbial fuel cells (MFCs) that generate electricity by the break-down of organic matter (e.g.waste water) have a great potential for the future energy and environmental challenges. MFCs are often compared with an aerobic digestion, which also uses microbial activity for breaking down organic matter in the absence of oxygen. Unlike an aerobic digestion, which is relatively well understood and already widely used in municipal wastewater treatment plants, MFCs have received far less attention and funding, hence the technology is still at laboratory level in its development. For example, a conventional an aerobic digestion reactor allows $1 \mathrm{~kg}$ of COD (chemical oxygen demand) to be converted to an energy amount of roughly $1 \mathrm{kWh}$. In the case of MFCs, only few studies have reported power generation exceeding this level, although $1 \mathrm{~kg}$ of COD can theoretically be converted to $4 \mathrm{kWh}$ (Ge et al., 2014). Yet MFCs have their own merits compared to an aerobic digestion. Firstly, 


\section{IJO-SCIENCE \\ (INTERNATIONAL JOURNAL ONLINE OF SCIENCE)}

ISSN: $2455-0108$

MFCs generate electricity directly from organic matter, whereas an aerobic digestion produces biogas consisting of methane, carbondioxide and other gases, which means that additional processes such as gas separation, purification and combustion are required in order toget usable forms of energy. Also this biogas is difficult to store, in addition to the fact that it contributes significantly to greenhouse gas emissions, when there are leakages. Secondly, MFCs can be operated at ambient temperature or even below $20{ }^{\circ} \mathrm{C}$, and at low substrate concentration levels (Cheng, Xing \&Logan, 2011; Catal et al., 2011; Gil et al., 2003; Pant et al., 2010). Anaerobic digestion, on the other hand, is quite sensitive to both parameters as it requires high temperature and high substrate concentration (Verstraeteet al., 2005). Considering all these aspects, MFC and an aerobic digestion technologies do not seem to be competitive, rather both can be complementary to each other.

\section{Microbial Fuel Cells}

Technically microbial fuel cells are one of several types of fuel cell. Fuel cells are defined as electrochemical devices that continuously convert fuels directly to electrical energy, as long as reactants are supplied to their electrodes (Larminie \& Dicks, 2003). In this way, fuel cells are distinguished from batteries, which stop producing electricity once the stored chemical reactants run out. For this reason, in earlier days, the same components used in conventional fuel cells were often employed in MFC studies. Most fuel cells are powered by hydrogen, which can be fed to the fuel cell system directly or can be generated within the fuel cell system by reforming hydrogen-rich fuels such as gasoline, methane, propane, diesel, methanol and ethanol. This is one of the major drawbacks in the hydrogen technology. In order to get hydrogen, are forming process is necessary because hydrogen in its raw form can be impure and difficult to store. For example
Volume II, Issue VII October 2016

today's global hydrogen production is $48 \%$ from natural gas, $30 \%$ from oil, and $18 \%$ from coal; water electrolysis accounts for only 4\% (World Nuclear Association, 2014). This reforming process is energy intensive and results in a considerable quantity of carbondioxide emissions (each tone of hydrogen produced gives rise to 11 tonnes of CO2)(World Nuclear Association, 2014). Moreover pure hydrogen gas must be pressurised or liquefied to be used. There fore hydrogen storage is again another energy consuming process. On the other hand, MFCs can utilize a wide range of fuels as long as they contain organic matter, and this flexibility of fuel is one advantage that makes MFCs standout. In theory, organic waste can be abundant, since organic detritus includes all human, animal and plant wastes, estuarine sediments, algal blooms, compost, sludge, leaf-litter, macro-algae, and floodwater.

The history of MFC began with the discovery of the link between electricity and metabolic processes of living organisms. In 1791, Luigi Galvani applied current to dead frog legs and observed the legs twitching. From this work, he realised that biological reactions and electric current are closely related. This is one of the first attempts into the study of bioelectricity or animal electricity as it was named at the time (Piccolino, 1998). In 1911, Potter published the earliest MFC report on the ability of microorganisms to transform organic substrates (chemical energy) into electricity (Potter, 1911). He demonstrated the production of electrical energy from living cultures of either Escherichia colior Saccharomyces. This was the first MFC proving that biological process produces bioelectricity (Bullen $e t$ al., 2006; Shukla et al., 2004). However this first discovery was nearly forgotten until 1931 when Cohen showed that a batch-biological fuel cell could produce more than $35 \mathrm{~V}($ Cohen, 1931).In the 


\section{IJO-SCIENCE \\ (INTERNATIONAL JOURNAL ONLINE OF SCIENCE)}

ISSN: $2455-0108$

1960s, the USA NASA space programme showed interest in biological fuel cell technology since it could convert organic waste in spaceships into electrical power (Putnam, 1971).Thanks to this, this technology drew some attention for a time, but it was soon replaced by other energy sources such as photovoltaic panels (Bullen et al., 2006; Davis \& Higson, 2007). In 1976, Rao identified a clear principle of the biological fuel cell (Rao et al., 1976). In the 1980s, H. Peter Bennetto succeeded in extracting electric power from MFCs by employing pure cultures to catalyse the oxidation of organics and utilizing artificial electron mediators to facilitate electron transfer in the anode (Bennetto et al., 1983; Roller et al., 1984; Bennetto et al., 1985). Habermann and Pommer (1991) demonstrated that additional exogenous mediators are not necessary for MFCs to generate electricity, since microorganisms could naturally produce such electron shuttle substances; this was also the first report of long-term wastewater utilisation using MFCs. Since then, rapid advances have been made in MFC research.

However MFC technology is still in its infancy due to the relatively short and interrupted development period. Unlike some conventional inorganic fuel cells that have already reached an advanced state in their development, only very few MFC systems with reactor volumes bigger than1L have been tested (The New York Times, 2007; Oxfam, 2015). MFCs nevertheless possess a great potential to bring about innovation and become true alternatives to fossil fuel energy generation. In the early 2000s, two robots, Chew-Chew and Eco Bot I, both powered by MFCs were developed (Wilkinson, 2000; Ieropoulos, Greenman \& Melhuish, 2003). Biochemical oxygen demand (BOD) measuring sensors using MFCs are commercially available (HABS 2000,
Volume II, Issue VII October 2016

KORBI) and benthic MFCs as on-site power sources for sensors and acoustic communication devices have also been reported (Reimers et al. ,2006). Recently a stack of 24MFCs successfully charged a commercially available mobile phone directly (Ieropoulos et al., 2013).

\section{Principle of MFC Electricity Generation}

MFCs are devices that convert chemical energy of feedstock into electricity through the metabolic activity of microorganisms. MFCs usually consist of two compartments; an anode and a cathode separated by an ionpermeable material. In the anode, microorganisms oxidize organic matter (fuel) and releaseCO2, electrons and protons. Electrons produced in the anode flow to the cathode via an external circuit as the result of electrophilic attraction from the cathode electrode, whilst protons migrate from the anode to the cathode through the separator between the two compartments. The electrons and protons subsequently combine with oxygen (final electron acceptor) and this reduction reaction completes the circuit (Figure2.4) (Li et al., 2008; Chae et al., 2008). The quantity of electrons flowing through the external circuit is the electricity being produced i.e. current.

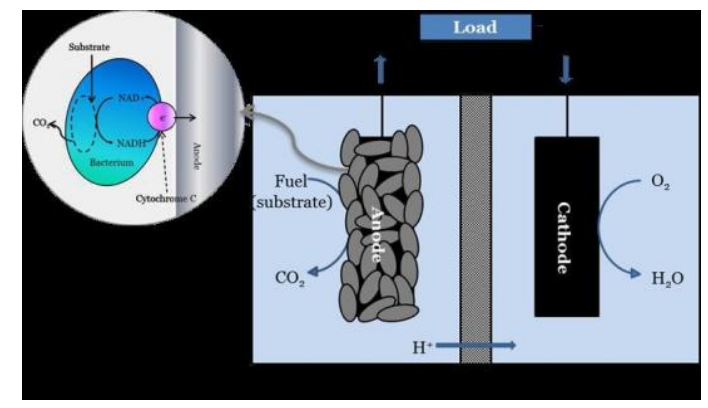

Fig: Electron donors and acceptors of MFCs

\section{Components and Materials}

\section{Anode}




\section{IJO-SCIENCE \\ (INTERNATIONAL JOURNAL ONLINE OF SCIENCE) \\ Volume II, Issue VII October 2016}

ISSN: $2455-0108$

Various materials have been investigated for MFC anodes in order to improve performance in terms of power output, durability and easier operation. Good anode materials are required to have large surface area for bacterial attachment and high electrical conductivity for the charge transfer, as well as good current collection capability. Since the anodes become biotic, they should be non-toxic to microorganisms, as well as inert to biochemical reactions. In order to prevent or minimize fouling, the structure of anodes needs to be carefully chosen. Also they should be robust for longterm operation and economical, in terms of cost of production.

Carbon based materials such as carbon cloth (Li et al., 2010; Santoro et al., 2011), carbon fibre veil (Ieropoulos, Greenman \& Melhuish, 2010; Winfield et al., 2011), graphite felt (Biffinger et al., 2007b; Aelterman et al., 2008) and graphite granules (Aelterman et al., 2006a; Jiang \& Li, 2009;Deekeet al., 2015) are the most commonly used materials in MFCs due to their chemical inertness, bio-fouling resistance, high conductivity, high surface area and relatively low cost. One of the limitations of these carbon based materials is clogging pores or spaces due to biofilm growth in systems running under poor fluid dynamics, which leads to anode electro catalytic efficiency deterioration. Furthermore high background currents of carbon materials were pointed out, which makes in depth study of anodophilic biofilms difficult (Babauta et al., 2012).

Metals such as gold (Crittenden, Sund \& Sumner, 2006; Richter et al., 2008), titanium (Heijne et al., 2008) and stainless steel (Pocaznoi et al., 2012) have been also employed for MFC anodes due to their excellent conductivity. Although some of these metal electrodes showed performance enhancement after surface modification, in order to improve the relatively small surface area and to introduce adhesive surfaces for bacterial attachment, when considering scale-up for waste/wastewater treatment, most of them seemed unsuitable as MFC anode due to the high cost, poor bacterial attachment or high risk of corrosion. Therefore physical or chemical surface modification seems indispensable for metal anodes. Some researchers have tried metal-carbon composite anodes (Park \& Zeikus, 2002, 2003; Lowy et al., 2006; Lowy \& Tender, 2008;Zhang et al., 2007; Chen et al., 2013). For these type of anodes, metals such as $\mathrm{Mn} 4+, \mathrm{Mn} 2+, \mathrm{Ni} 2+$, $\mathrm{Sb}(\mathrm{V})$ and aluminium-alloy mesh were applied with carbon based materials such as graphite rod, graphite paste and carbon cloth. These attempts showed anode performance improvement. However further studies about cost evaluations, longterm stability, and understanding the mechanism of bacterial interaction with anode surface are required.

Diverse modifications have been made in order to improve the anode performance. This includes ammonia treatment of anode surface (Cheng \& Logan, 2007; Velasquez-Orta, Curtis \& Logan, 2009), acid treatment (Scottet al., 2007; Feng et al., 2010) and adding nano structured materials (Sun et al., 2010; Fan $e$ $t$ al., 2011; Xiao et al., 2012). Especially nano structured materials such as carbon nanotubes (CNTs), grapheme (G) seem promising in terms of increasing power output. Coating anode materials with conductive polymers like polyaniline (PANI) or polypyrrole (PPY) also have received much attention due to high conductivity, good redox properties, environmental stability and relatively straight forward synthesis.

In order to enhance the anode performance, anode modification is thought to be an effective strategy. For 


\section{IJO-SCIENCE \\ (INTERNATIONAL JOURNAL ONLINE OF SCIENCE)}

ISSN: $2455-0108$

waste/wastewater clean-up, however, long-term stability is an essential requirement thus more attention needs to be given in this aspect. An increasing risk for fouling due to biofilm growth in the anode structure also needs to be considered.

\section{Cathode}

In earlier years, MFC research mainly focused on the anode, because it was a unique feature that makes MFCs different to other conventional fuel cells. When considering the overall process, however, the cathode reaction is one of the major limiting factors of the FC technology and in-depth research on the cathode side needs to be carried out, since different approaches to the MFC cathodes is required compared to other types of fuel cells, running at high temperatures and relatively rapid reaction rates. Recent work has started to focus more on the cathode but still most studies use expensive catalysts or unsustainable electrolytes ( $\mathrm{Lu} \& \mathrm{Li}, 2012$ ). Platinum is the most commonly used catalyst for oxygen reduction in the cathode due to its satisfactory catalytic ability (Liu \& Logan, 2004; Oh, Min \& Logan, 2004; Pham et al., 2004). Adding platinum, however, brings high costs for the system build-up. Ferricyanide is a very reliable laboratory standard, with a good performance, however it is limited because of its environmental toxicity to other living systems and frequent need for replenishment after consumption.

Recently, some researchers turned their attention to bio-cathodes and suggested several possible advantages of using such systems instead of a biotichalfcells (Aldrovandi et al., 2009; Mao et al., 2010). This may reduce the cost for system set-up and operation by eliminating the use of expensive catalysts. In addition, MFCs with bio-cathodes become more sustainable as there is no need for catalyst replenishment/replacement. Aelterman et al.(2006b) demonstrated the microbial

\section{Volume II, Issue VII October 2016}

reduction of $\mathrm{Fe}(\mathrm{III})$ and $\mathrm{Mn}(\mathrm{IV})$, which can take the role of terminal electron acceptors in the cathode, as an alternative method of extracting those metals from minerals. Rabaey and Keller (2008) showed current increases by growing a biofilm onto a cathode in comparison to anon-catalysed control and Gajda et al. (2013) achieved improvement of power generation using photosynthetic cathodes consisting of phototrophic organisms.

Another approach to resolve the catalyst problem is to increase the size of the cathode in proportion to the anode (Freguia et al., 2007; Nevin et al., 2008). Zuo et al. (2007) showed power output improvement with higher surface area of the cathode, but this change resulted in a constant volumetric power density since the volume of the cathodic chamber was required to be increased in order to accommodate for the larger cathodes. Removing the cathodic chamber can be a good option to avoid this kind of problem. Hence single chamber MFCs with open to air cathodes (i.e. R-MFC (B) and C-MFC described in section 3.2.1) have been widely used (Wei, Liang \& Huang, 2011; El-Chakhtoura et al ,2014; Gnana Kumar et al., 2014; Papaharalabos et al., 2014; Chen et al., 2015). Compared to aqueous cathodes, which are submerged in the cathodic chambers, open to air cathodes seem to be a more attractive option for practical applications with better performance and no need for active aeration.

Cathode surface modification for higher surface area (Wang et al., 2011) or catalytic efficiency (Duteanu et al., 2010; Wang et al., 2014) has been studied actively in the recent years. Non-Pt cathodes have been investigated to reduce the cathode material cost but still to enhance the ORR kinetics. Low-cost nonprecious metals and metal oxides such as 


\section{IJO-SCIENCE \\ (INTERNATIONAL JOURNAL ONLINE OF SCIENCE)}

ISSN: $2455-0108$

cobalt, manganese dioxide, cobaltetramethyl phenylporphyrin, pyrolyzed$\mathrm{Fe}(\mathrm{II})$ phthalocyanine, lead dioxide, metal porphyrins and phthalocyanines have shown good performance comparable to Pt cathodes (Zhao et al., 2005, 2006; Morris et al., 2007; HaoYu et al., 2007; $\mathrm{Yu}$ et al., 2008; Lefebvre et al., 2009; Zhang et al., 2009). Nevertheless, the chance of metal discharge from the cathode and sensitivity of metal-based catalysts towards elevated $\mathrm{pH}$ values on the cathode should not be overlooked for practical applications of the MFC technology. Santoro et al. (2012) demonstrated platinum free cathodes modified with the addition of micro porous layer (MPL), which outperformed platinum-based cathodes in a long term study. The same type of electrode was applied as the anode for a part of this work (section 4.2) which was a collaboration between three research groups; Bristol Bio Energy Centre (UK), Center for Clean Energy Engineering (USA) and RSE-Ricercasul Sistema Energetico S.p.A. (Italy).

\section{Ion exchange membrane (IEM)}

The IEM is primarily used to physically separate the anode from the cathode whilst allowing protons to travel through to the cathode. The use of IEMs, however, has its drawbacks. The membrane contributes significantly to the internal resistance of a MFC and delays proton transfer from the anode chamber to the cathode chamber (Gilet al., 2003; Rozendal, Hamelers \& Buisman, 2006). In addition, it increases the overall cost of a MFC system. Previous work has shown that single-chamber MFCs without IEMs produce a higher power density than MFCs with Nafion ${ }^{\circledR}$ membranes, which are the most commonly used IEM in MFCs (Liu \& Logan, 2004; Liu, Cheng \& Logan, 2005; Yang, Jia \& Liu, 2009). However it has also been reported that the lack of IEM would

\section{Volume II, Issue VII October 2016}

increase oxygen and substrate diffusion, which would result in a reduction of microbial catalytic activity and consequently in a reduction in Coulombic efficiency (Zhang et al., 2010). In this sense, a form of separator in the MFC is necessary (Lefebvre et al., 2011;Li et al., 2011.

\section{Conclusion}

Although attempts of using alternative materials to the IEM, (Biffinger et al., 2007b; Venkata Mohan, Veer Raghavulu \& Sarma, 2008; Sunet al., 2009; Zhuang et al., 2010a), IEMs are still widely used in MFC research due to their good performance. The most commonly used IEMs in MFCs are cation exchange membranes (CEMs) especially Nafion®. However it has been shown that relatively higher concentration of cation species, other than protons such as, $\mathrm{Na}+, \mathrm{K}+, \mathrm{Ca} 2+, \mathrm{Mg} 2+$ and $\mathrm{NH} 4+$ transfer positive charge through the membrane (Rozendal, Hamelers \& Buisman, 2006). Retarded proton transfer leads to $\mathrm{pH}$ splitting between the two chambers, and this gives a negative effect on microbial activity in the anode chamber and also reduces the cathode potential (Kim, Chang \& Gadd,2007; Torres, Kato Marcus \& Rittmann, 2008; Harnisch, Schröder \& Scholz, 2008). Anion exchange membranes (AEMs) have also been tested in MFCs and several studies have reported better performance compared to CEMs (Kim et al., 2007; Mo et al., 2009) because of the $\mathrm{pH}$ splitting problem of CEMs.

\section{References}

1. Aelterman P, Rabaey K, Pham HT, Boon N, Verstraete W (2006) Continuous electricity generation at high voltages and currents using stacked microbial fuel 


\section{IJO-SCIENCE \\ (INTERNATIONAL JOURNAL ONLINE OF SCIENCE) \\ Volume II, Issue VII October 2016}

ISSN: 2455-0108

cells. Environ Sci Technol 40: 33883394.

2. Bond DR, Holmes DE, Tender LM, Lovley DR (2002) Electrodereducing microorganisms that harvest energy from marine sediments. Science 295: 483-485.

3. Catal $\mathrm{T}$, Li K, Bermek $\mathrm{H}$, Liu $\mathrm{H}$ (2008) Electricity production from twelve monosaccharide using microbial fuel cells. J Power Sources 175: 196-200.

4. Dewan A, Donovan C, Heo D, Beyenal H (2010) Evaluating the performance of microbial fuel cells powering electronic devices. J Power Sources 195: 90-96.

5. Emde R, Swain A, Schink B (1989) Anaerobic oxidation of glycerol by Escherichia coli in an amperometric poised-potential culture system. Appl Microbiol Biotechnol 8: 170-175.

6. Foley M, Rozendal RA, Hertle CK, Lant PA, Rabaey K (2010) Life cycle assessment of high-rate anaerobic treatment, microbial fuel cells, and microbial electrolysis cells. Environ Sci Technol 4: 3629-3637.

7. Gottesfeld S, Zawodzinski TA (1997) Polymer electrolyte fuel cell. Adv Electrochem Sci 5: 195-301.

8. Harnisch F, Schröder U (2009) Selectivity versus mobility: Separation of anode and cathode in microbial bioelectro chemical systems. ChemSusChem 2: 921-926.
9. Jang, JK (2004) Construction and operation of a novel mediator-and membrane-less microbial fuel cell. Process Biochem 39: 1007-1012.

10. Pant D, Van Bogaert G, Diels L, Vanbroekhoven K (2010) A review of the substrates used in microbial fuel cells (MFCs) for sustainable energy production. Bioresour Technol 101: 1533-1543.
11. Rabaey K, Boon N, Hofte M, Verstraete W (2005a) Microbial phenazine production enhances electron transfer in biofuel cells. Environ Sci Technol 39: 3401-3408. 


\section{IJO-SCIENCE}

(INTERNATIONAL JOURNAL ONLINE OF SCIENCE)

ISSN: $2455-0108$

Volume II, Issue VII October 2016

12. Selembo PA, Perez JM, Lloyd WA, Logan BE (2009) High hydrogen production from glycerol or glucose by electrohydrogenesis using microbial electrolysis cells. Int J Hydrogen Energy 3: 5373-5381.

13. Trinh NT, Park JH, Kim BW (2009) Increased generation of electricity in a microbial fuel cell using Geobacter sulfurreducens. Korean J Chem Eng 26: 748-753. 